\title{
MCA MEAN BLOOD FLOW VELOCITY INDEX - A PROMISING PREDICTOR OF INTRACRANIAL HEMORRHAGE AFTER STROKE THROMBECTOMY
}

Markus Kneihsl (MD)a, Kurt Niederkorn (MD)a, Hannes Deutschmann (MD) $)^{b}$, Christian Enzinger (MD) ${ }^{a, b}$, Birgit Poltrum (MD) ${ }^{a}$, Daniela Thalera, Isabella Colonna (MD)a, Gerhard Bachmaier (PhD)c, Franz Fazekas $(\mathrm{MD})^{\mathrm{a}}$ and Thomas Gattringer (MD, PhD) ${ }^{\mathrm{a}}$

a Department of Neurology, Medical University of Graz, Graz, Austria

${ }^{b}$ Division of Neuroradiology, Vascular and Interventional Radiology, Department of Radiology, Medical University of Graz, Graz, Austria

c Institute of Medical Informatics, Statistics and Documentation, Medical University of Graz, Graz, Austria

\section{Background and Purpose}

Recent studies indicated that an increased middle cerebral artery (MCA) mean blood flow (MBF) velocity on transcranial duplex sonography (TCD) was associated with intracranial hemorrhage $(\mathrm{ICH})$ after successful endovascular recanalization of anterior circulation vessel occlusion ${ }^{1,2}$. This study aimed to further determine the predictive value of the MCA MBF velocity for postthrombectomy $\mathrm{ICH}$.

\section{Methods}

Over a seven-year period, we reviewed all ischemic stroke patients with successful endovascular recanalization for anterior circulation vessel occlusion ( $\mathrm{TICl} 2 \mathrm{~b}-3)$ at our center. Postinterventional TCD sonography served to identify MCA MBF velocity indices (=MBF velocity of the recanalized divided by the contralateral MCA). Receiver operating characteristic (ROC) curve tested the ability of MCA MBF velocity index values in predicting $\mathrm{ICH}$ after thrombectomy.

\section{Results}

Of 178 ischemic stroke patients (mean age: $67 \pm 12$ years, female: $43 \%$ ) with successful anterior circulation thrombectomy, 35 patients had postinterventional $\mathrm{ICH}$ (symptomatic: 10, asymptomatic: 25). MCA MBF velocity index was increased in $\mathrm{ICH}$ compared to non- $\mathrm{ICH}$ patients $(1.32 \pm 0.39$ versus $1.02 \pm 0.32$, $\mathrm{p}<0.001)$. The area under the ROC curve for MCA MBF velocity index values in the prediction of $\mathrm{ICH}$ after stroke thrombectomy was 0.69 (95\% Cl: 0.59-0.79). The cut-off point with the highest sensitivity and specificity was set at 1.25 (sensitivity 69\%, specificity $73 \%$ ) and had a negative predictive value for $\mathrm{ICH}$ of 91\%. Figure 1 shows images from a representative case.

\section{Conclusions}

This study supports a predictive role of TCD sonography detected MCA MBF velocity index for $\mathrm{ICH}$ after stroke thrombectomy. In patients with MCA MBF velocity indices below 1.25 postinterventional $\mathrm{ICH}$ appears rare.

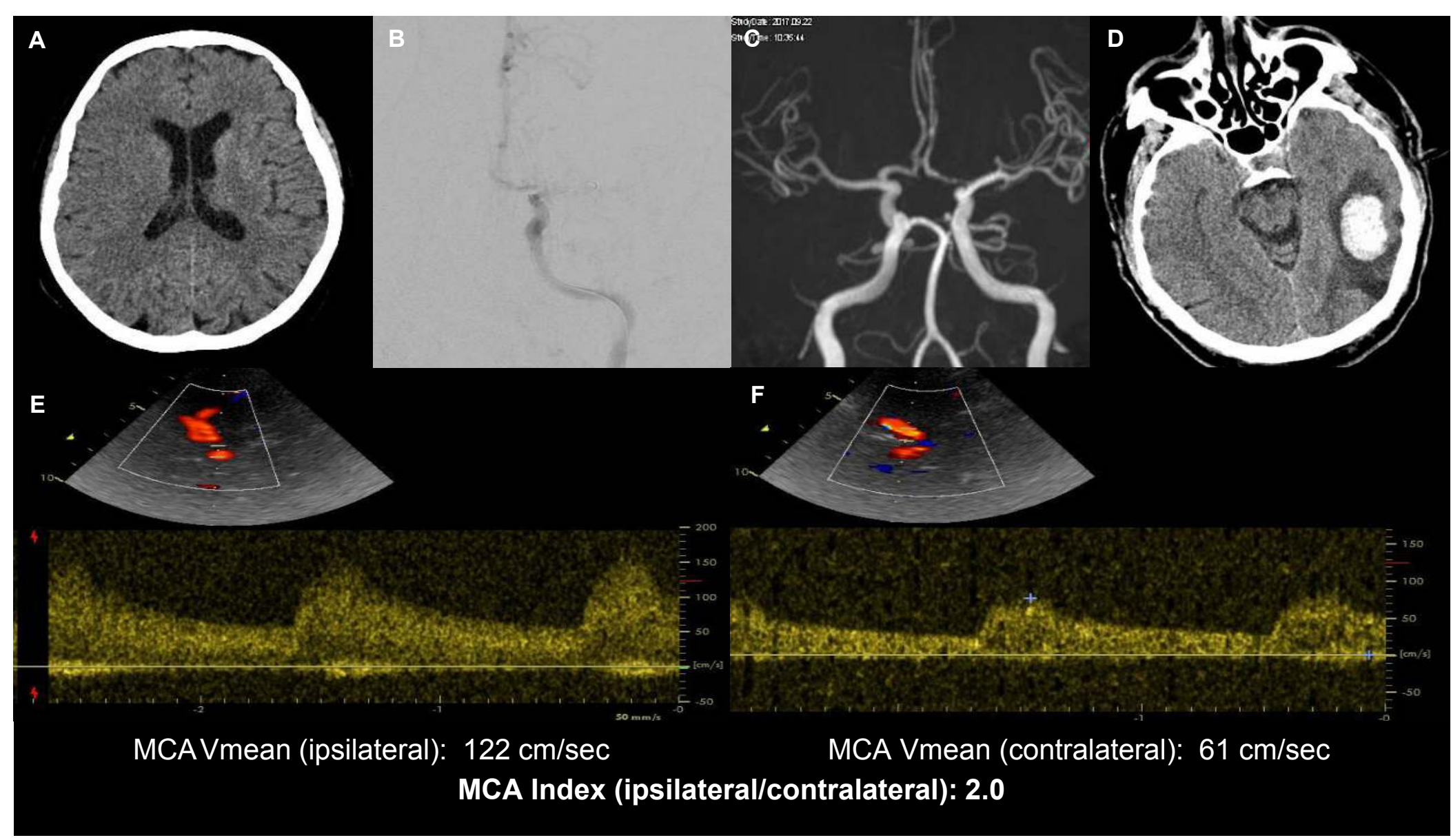

Figure 1. Representative images of a 64 years old patient with acute left intracranial ICA occlusion (NIHSS at presentation: 11)

A) Preinterventional brain CT 60 minutes after symptom onset did not detect any early infarct signs. CT angiography shows a distal ICA occlusion, which was confirmed via DSA (B)

C) TOF-MRA after successful $\mathrm{TICI} 3$ recanalization shows ICA/MCA reperfusion. CT follow-up (65 hours after intervention) reveals a parenchymal $\mathrm{ICH}(\mathrm{D})$.

E) and F) Postinterventional TCD sonography 23 hours after recanalization shows a much higher MBF velocity in the recanalized compared to the contralateral MCA.

Abbrevations : CT: Computed tomography, ICA: Internal carotid artery, TOF-MRA: Time of flight-magnetic resonance imaging, TICI: Thrombolysis in cerebral infarction scale, MCA Middle cerebral artery, ICH: Intracranial hemorrhage, TCD: Transcranial Duplex sonography

${ }^{1}$ Kneihsl M, Niederkorn K, Deutschmann H, et al. Increased middle cerebral artery mean blood flow velocity index after stroke thrombectomy indicates increased risk for intracranial hemorrhage. J Neurointerv Surg. 2017. pii: neurintsurg-2017-013617.

${ }^{2}$ Varela R, Silva A, Lopes J, et al. Early transcranial color-coded Doppler in the predicton of post-thrombectomy reperfusion lesion. Eur J Neurol. 2018 , 25 (Suppl. 1), 1-65. 